\title{
The Examination of the Growth of Escherichia coli (E. coli) Strain on Mac Conkey Agar Prepared with Wastewater
}

\author{
Buse Sabiha Bozaslan, Huseyin Cakan, Perihan Seda Ates, A. Ata Alturfan, and Salih Cengiz
}

\begin{abstract}
Wastewater is a combination of the liquid wastes conducted away from residences, hospitals and industrial establishments and treatment of wastewater is crucial for environmental and public health as treated wastewater is reused in many ways including drinking water. In a wastewater treatment plant, microorganisms and toxic chemical compounds are removed from wastewater by physical, chemical and biological methods to generate effluent wastewater. Microorganisms play a critical role in activated sludge systems.

A culture media is defined as a solid or liquid preparation used for the growth, transport, and storage of microorganisms which must contain all the nutrients required for the growth of the microorganism. The function of the media depends on its composition as well as the nutrients needed for the growth of all bacteria. It has been suggested that, no definitive standart exists for the assessment of culture media.

Herein, the aim of our study was to evaluate the effects of influent and effluent wastewater samples used in Mac Conkey agar on the growth of E. coli. Our preliminary results showed that influent wastewater was more effective on bacterial growth compared to effluent wastewater. The results of our preliminary findings need to be strengthtened with additional studies conducted using wastewater samples.
\end{abstract}

Index Terms-Mac Conkey agar, E.coli, toxic chemicals, wastewater, nutrients.

\section{INTRODUCTION}

The production of waste from human activities is unavoidable. This waste will end up as wastewater. In literature, wastewater has been described as "a combination of the liquid wastes conducted away from residences, offices, business premises and institutions as well as from industrial establishments, where such ground, surface and storm water may also be admitted to or find its way into the sewers", by the Committee on Sewerage and Sewage Disposal of the American Public Health Association. Therefore, wastewater is constructed from residential sources that are used, going down the drain from baths, sinks, dishwashers and toilets and also from commercial and industrial sources [1], [2].

Treatment of wastewater is crucial for environment and public health, as treated wastewater is reused in a many ways, including drinking water, golf course irrigation, cooling water for power plants and oil refineries, processing water for mills, plants, toilet flushing, construction activities, concrete mixing, artificial lakes, etc [2].

Manuscript received November 15, 2016; revised January 30, 2016.

Buse Sabiha Bozaslan and Perihan Seda Ates are with Forensic Sciences Institute, Cerrahpaşa Medical Faculty, Turkey.

Salih Cengiz, A. Ata Alturfan, and Huseyin Cakan are with the Department of Institute of Forensic Sciences, Istanbul University, Turkey (e-mail: ataalturfan@gmail.com).
On the other hand if wastewater is not adequately treated spreading of diseases, fish kills and destruction of other forms of aquatic life may occur. The pollution of water has deleterious effects on all living creatures. The mission of a wastewater treatment plant is to treat the wastewater before it is returned to the environment. Therefore in every developing and developed country, wastewater treatment plants operate at a critical point of the water cycle, preventing the water from excessive pollution [2]-[4].

In wastewater treatment, most of the pathogenic microorganisms and toxic chemical compounds are removed from wastewater by physical, chemical and biological methods. Measuring the quality of influents and effluents has critical importance as it reflects the performance of the plant. Besides, microorganisms play a critical role in the of activated sludge systems [4], [5].

In wastewater treatment plants an aerobic activated sludge system decomposes organic compounds via microorganisms. Microorganisms grow on the aerated organic matter and the newly formed microbial biomass is eventually consumed to meet maintenance energy needs [2]-[4]. Finally, wastewater effluent is produced as the final product of all earlier treatment processes, which can be discharged to a stream, river, bay, lagoon or wetland and can be used to irrigate parks, corps or to recharge groundwater and additionally it can also be used in industrial applications as well [5].

In literature, a culture media is defined as a solid or liquid preparation used for the growth, transport, and storage of microorganisms which must contain all the nutrients required for the growth of a microorganism. In culture media, usually tap water or distilled water is preferably used [6].

Escherichia coli (E. coli) was first isolated from the feces of a child in 1885 by the Austrian pediatrician Theodor Escherich [7]. E. coli is the common and most prevalent inhabitant of terminal small intestine and large intestine of human and many warm blooded animals belonging to Enterobacteriaceae family [8]-[10]. They are the most abundant facultative anaerobes and nonsporeforming bacilli in the environment [10], [11]. The optimum $\mathrm{pH}$ for E. coli growth is 6 to 8, however, growth can occur as low as $\mathrm{pH} 4$ and as high as $\mathrm{pH} 9$ as well. The optimal conditions for growth are a temperature of $37^{\circ} \mathrm{C}$. It can survive between $4-45^{\circ} \mathrm{C}$. On the otherhand vegetative cells killed by pasteurization and excess heat [7], [10], [12]. E. Coli is almost $0.5 \mu \mathrm{m}$ in diameter and $1.0-2.0 \mu \mathrm{m}$ in length. Within the periplasm, single (thickness of $2.5 \mathrm{~nm}$ ) to three layered ( $7 \mathrm{~nm}$ thick) of peptidoglycan can be found. E. coli are commonly motile in liquid by means of peritrichous flagella. It can be found secondarily in soil and water as a consequence of fecal contamination. In general, its determination has been used as an indicator of poor water 
quality [13]-[15]. Most strains of E. coli are harmless and healthy intestinal tract can synthesize vitamin K2 by the help of these bacterial strains. Moreover, it supresses the growth of several pathogenic bacteria [16] .

Consequently,, the aim of our study was to evaluate the effects of influent and effluent wastewater samples used in Mac Conkey agar on the growth of E. coli.

\section{MAteriALS AND METHODS}

\section{A. Preparing Media with Wastewater}

Influent and effluent wastewater samples collected between May and August from wastewater treatment plant in Istanbul in 2015 were used as study material. Samplesweretransported in steriled glass bottles with screw cap in opaque special transport containers to microbiology laboratory. After collection of samples, they were immediately transported to laboratory on ice and studied on the same day.

\section{B. Growth Media Prepared Using Wastewater}

Growth mediawas prepared using wastewater according to the standard procedures to produce the Mac Conkey agar media. MacConkey Agar is generally used for the selective isolation and identification of Enterobacteriaceae family from feces, urine, water, wastewater and foods. It's selective and differential culture media containing peptons, bile salts, lactose, crystal violet, $\mathrm{NaCl}$, neutralreddye, agarandwater. It isolates Gram-negative and enteric bacteria and differentiate them based on the lactose fermentation [16]-[19]. Then, mediawassterilized for 15 minutes at $121^{\circ} \mathrm{C}$ in an autoclave and was cooled down to $40-50^{\circ} \mathrm{C}$ and was poured into petri dishes. Plates were stored in the refrigerator after they were solidified.

\section{Growth Media Prepared Using Distilled Water}

The same procedure was applied for standard media [17]-[19].

\section{E. coliIdentification of WastewaterSamples}

Wastewater samples were brought to laboratory in $300 \mathrm{ml}$ opaque sterile glass bottles with screw cap in special transport containers and diluted in specific proportions for microbiological examination. The prepared samples were inoculated on Mac Conkey agar, plates were incubated at $36.5^{\circ} \mathrm{C}$ for $24-48$ hours and the colonies were observed. Agar plates with bacterial growth were examined macroscopically and microscopically.

After macroscopic examinations, colonies were transferred onto slides using a needle and were stained with various painting methods. Then they were microscopically examined and photographed under a light microscope. At the end of microscopic examinations classical biochemical tests,Indole, Methyl red, Voges-Proskauer, Citrate (IMVIC) tests, triple sugar iron agar(TSI) tests and API kits were performed for accurate species identification.

The identified E. coli species were inoculated on Mac Conkey agar prepared by using wastewater and distilled water at $36.5{ }^{\circ} \mathrm{C}$ for $24-48$ hours to interprete the growth densities.

\section{RESUlTS}

Biochemical diagnostic test result for $E$. coli (IMVIC tests $+,+,-,-)$ was evaluated. $\mathrm{H}_{2} \mathrm{~S}$ formation was not observed in TSI media, yellow acid reaction was observed both in the bottom and on the surface of the media. E.coli was found to give an opaque image as brick red color colonies on Mac Conkey agar. E.coli strains were confirmed with rapid identification of the samples with high standard API test.

In our preliminary study, 10 wastewater samples (as 5 influent and 5 effluent samples) obtained from wastewater treatment plant at different time points were used to prepare the Mac Conkey agar. The results of E.coli growth of each sample is given in Table I and the averages of the results are given in Table II.

E. coli growing areas were evaluated on the standard prepared media plates and on the media plates with wastewater samples. An average of 90 colonies were examined on Mac Conkey agar media prepared with influent wastewater obtained from treatment plant $\left(10^{-2}\right.$ dilution) whereas 66 colonies were observed on the media prepared with effluent wastewater obtained from treatment plant $\left(10^{-2}\right.$ dilution). As controls, Mac Conkey agar prepared with distilled water was observed to have 95 colonies of E.coli (Table II).

E.coli growing areas were evaluated on the standard prepared media plates and on the media plates with wastewater samples after $10^{-3}$ dilution as well. An avarage of 18 colonies were examined on Mac Conkey agar media prepared with influent wastewater $\left(10^{-3}\right.$ dilution) whereas 13 colonies were observed on the media prepared with effluent wastewater $\left(10^{-3}\right.$ dilution). Mac Conkey media prepared with distilled water was observed to have 20 colonies of E.coli (Table II).

TABLE I: E. COLI GROWTH REPRESENTED AS COLONY COUNTONMAC CONKEY AGAR

\begin{tabular}{|l|l|l|l|l|l|l|l|l|l|l|}
\hline & \multicolumn{2}{|c|}{ Sample 1 } & \multicolumn{2}{|c|}{ Sample 2 } & \multicolumn{2}{c|}{ Sample 3 } & \multicolumn{2}{c|}{ Sample 4 } & \multicolumn{2}{c|}{ Sample 5 } \\
\hline Dilution & $10^{-2}$ & $10^{-3}$ & $10^{-2}$ & $10^{-3}$ & $10^{-2}$ & $10^{-3}$ & $10^{-2}$ & $10^{-3}$ & $10^{-2}$ & $10^{-3}$ \\
\hline $\begin{array}{l}\text { Control } \\
\text { (Colonies) }\end{array}$ & 113 & 27 & 92 & 11 & 107 & 29 & 89 & 13 & 72 & 19 \\
\hline $\begin{array}{l}\text { Influent } \\
\text { (Colonies) }\end{array}$ & 95 & 22 & 79 & 10 & 88 & 32 & 66 & 11 & 123 & 14 \\
\hline $\begin{array}{l}\text { Effluent } \\
\text { (Colonies) }\end{array}$ & 63 & 17 & 48 & 8 & 74 & 18 & 54 & 12 & 91 & 10 \\
\hline
\end{tabular}

TABLE II: AVERAGE E. COLI GROWTH REPRESENTED AS COLONY COUNTONMAC CONKEY AGAR

\begin{tabular}{|l|l|l|}
\hline & \multicolumn{2}{|c|}{ COUNTONMAC CONKEY AGAR } \\
\hline Control & $\mathbf{1 0}^{-2}$ dilution & $\mathbf{1 0}^{-3}$ dilution \\
\hline Influent & 95 Colonies & 20 Colonies \\
\hline Effluent & 90 Colonies & 18 Colonies \\
\hline
\end{tabular}

\section{DISCUSSION}

The appropriate culture media is very important for the growth of microorganisms in laboratory conditions. For the analysis of water and food, microorganism identification as well as analyzing antibiotic sensitivities, some specialized media has been used by microbiologists since the nineteenth century. Although the use of rapid methods increase, most of the techniques applied in the pharmaceutical quality control laboratories still need growth media [17]. 
Therefore culture media is of fundamental importance for most microbiological tests in order to obtain pure cultures to grow and count microbial cells and to cultivate and select microorganisms. Without the appropriate and high-quality media, achieving accurate, reproducible and repeatable microbiological test results would be very difficult [17], [18]. A microbiological culture media can be defined as a substance that encourages the growth, support, and survival of microorganisms. Accordingly, a culture media contains nutrients, growth promoting factors, energy sources, salt, minerals, metals, and gelling agents [19].

E. coli ATCC 25922 is a nonpathogenic strain of $E$. coli. It is also easily cultured, well charaterized as lactose fermenting Gram negative bacteria and additionally studied as a model organism in the field of microbiology and biotechnology [16], [20]-[22]. Lactose fermenting bacteria likeE. coli develop as red or pink color due to the acid production from lactose. Precipitated bile salts are observed around the proliferated colonies.Theredcolor is dueto the production of acid from lactose. When the $\mathrm{pH}$ of media drops below 6.8 , absorption of neutral red and a subsequentcolorchange of the dye occurs. Bacteria that can't have the ability to ferment lactosearecolorlessandtransparent. The selective action of Mac Conkey agar is attributed to bile salts and crystal violet dye, as they have inhibitory effects on most of the Gram positive bacteria and conversely, Mac Conkey agar allow gram-negative organisms to grow. For these reasons, Mac Conkey agar is generally referred as "selective-differential" media [16]-[19].

It has been suggested that no one definitive standart exists for the assessment of culture media [19]. Under the light of these data, the aim of our study was to evaluate the effects of influent and effluent wastewater samples used in Mac Conkey agar on the growth of E. coli. Our preliminary results showed that influent wastewater was more effective on bacterial growth compared to effluent wastewater. The number of colonies observed on culture media prepared using the effluent wastewater were less than that of the culture media prepared using the influent wastewater and the control Mac Conkey media.

Although all microorganisms need sources of energy, nitrogen, carbon, phosphorus, sulfur, and various minerals, the exact composition of a satisfactory media depends on the species to be identified as nutritional requirements differ among the microorganisms. Therefore, it is important to know microorganism's normal habitat to select a suitable culture media since its nutrient requirements reflect its natural surroundings. The function of the media also depends on its composition as well as the nutrients needed for the growth of all bacteria. Moreover, some special-purpose media contain one or more chemical compounds that are essential for their functional specificity [1]-[4].

Wastewater constituted from residential sources contain the necessary nutrients for the growth of bacteria. In our case, wastewater was constructed mainly from domestic sources and mostly greywater and blackwater. Chemically, wastewater is made up of organic and inorganic compounds. Organic compounds are mainly carbohydrates, proteins and fats which reflects the diet of the people. Carbohydrates and proteins are perfect diet for bacteria. On the other hand, in organics are consist of heavy metals, nitrogen, nitrate, nitrite, ammonium ions, phosphorus, sulphur, chlorides and other toxic compounds. During the treatment processes, most of the essential organic materials such as nitrogen and phosphorus are removed during the secondary treatment. This may be the reason for the reduced bacterial growth in culture medium prepared with the effluent wastewater.

To the best of our knowledge, this is the first study in literature that investigates the effects of wastewater samples in culture media on the growth of bacteria. The results of our preliminary findings need to be strengthened with additional studies.

\section{REFERENCES}

[1] L. Metcalf and H. P. Eddy, Wastewater Engineering, 1st ed. New York, U.S.A.: McGraw-Hill, 1972, ch. 2, pp. 32-154.

[2] A. Kaur, S. Ghosal, N. B. Shinver, and M. Z. A. Khan, "Recycling of water: A review on wastewater treatment," Int. J. Pure App. Biosci, vol. 2, pp. 318-326, March 2014.

[3] L. Metcalf and H. P. Eddy, Wastewater Engineering, 3rd ed. New York, U.S.A.: McGraw-Hill, 1991, ch. 2, pp. 29-137.

[4] L. Metcalf and H. P. Eddy, Wastewater Engineering, 4th ed. New York, U.S.A.: McGraw-Hill, 2003, ch. 1, pp. 1-25.

[5] S. K. Sharma and R. Sanghi, Wastewater Reuse and Management, 1st ed. Springer, 2013, ch. 5, pp. 127-164.

[6] A. Brown, Benson: Microbiological Applications Lab Manual, 8th ed. New York, U.S.A.: McGraw-Hill, 2001, ch. 20, pp. 76-81.

[7] T. Escherich, "Die darmbakterien des neugeboren und sauglings," Fortschr. Med, vol. 3, no. 2, pp. 515-522, May 1885.

[8] R. I. Mackie, A. Sghir, and H. R. Gaskins, "Developmental microbial ecology of the neonatal gastrointestinal tract," Am. J. Clin. Nutr., vol. 69, no. 5, pp. 1035-1045, May 1999.

[9] P. H. Gilligan, "Identification of pathogens by classical clinical tests," The Prokaryotes - Human Microbiology, Springer, Verlag Berlin Heidelberg, 2013, ch. 4, pp. 57-89.

[10] M. H. Serres and M. Riley, "Volume 1: Symbiotic associations, biotechnology, applied microbiology, genomics and metabolism in Escherichia coli," The Prokaryotes, Springer, Verlag Berlin Heidelberg, 2006, ch. 1, pp. 261-274.

[11] M. Bermudez and T. C. Hazen, "Phenotypic and genotypic comparison of Escherichia coli from pristine tropical waters," Appl. Environ. Microbiol., vol. 54, no. 2, pp. 979-983, April 1988.

[12] M. P. Doyle and J. L. Schoeni, "Survival and growth characteristics of Escherichia coli associated with hemorrhagic colitis," Appl. Environ. Micrbiol., vol. 8, no. 4, pp. 855-856, Oct. 1984.

[13] R. M. Harshey, "Bees aren't the only ones: Swarming in Gram-negative bacteria," Molec. Microbiol., vol. 13, no. 3, pp. 389-394, Aug 1994.

[14] L. Gan, S. Chen, and G. J. Jensen, "Molecular organization of Gram-negative peptidoglycan," Proc. Natl. Acad. Sci. U S A., vol. 105, no. 48 , pp. 18953-18957, Dec. 2008.

[15] R. A. Welch, "The Genus Escherichia," The Prokaryotes - Human Microbiology, Springer, 2006, ch. 3, pp. 60-71.

[16] V. Sharma, K. Suvarna, R. Meganathan, and M. E. Hudspeth, "Menaquinone (vitamin K2) biosynthesis: Nucleotide sequence and expression of the menB gene from Escherichia coli," J. Bacteriol., vol. 174, no. 15, pp. 5057-5062, Aug. 1992.

[17] A. Cundell, "Review of media selection and incubation conditions for the compendial sterility and microbial limits tests," Pharmaceutical Forum, vol. 28, no. 6, pp. 2034-2041, Nov. 2002.

[18] T. Sandle, "Selection of microbiological culture media and testing regimes," Microbiology and Sterility Assurance in Pharmaceuticals and Medical Devices, New Delhi: Business Horizons, 2010, ch. 2, pp. 101-120.

[19] E. Y. Bridson and A. Brecker, "Designs and formulation of microbial culture media," Methods in Microbiology, 1st ed. vol. 3A, London: Academic Press, 1970, pp. 229-296.

[20] J. R. Lobry, G. Carret, and J. P. Flandrois, "Maintenance requirements of Escherichia coli ATCC 25922 in the presence of sub-inhibitory concentrations of various antibiotics," J. Antimicrob. Chemother., vol. 29, no. 2, pp. 121-127, Feb. 1992.

[21] J. V. Uri, "Is Escherichia coli ATCC 25922 a colicin producing strain?" Acta. Microbiol. Immunol. Hung., vol. 41, no. 2, pp. 215-219, Feb. 1994. 
[22] A. Sauer and C. I. Moraru, "Inactivation of Escherichia coli ATCC 25922 and Escherichia coli O157:H7 in apple juice and apple cider, using pulsed light treatment," J. Food. Prot. vol. 72, no. 5, pp. 937-944, May 2009.

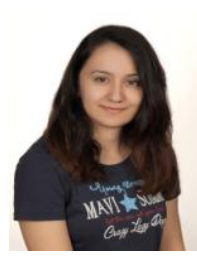

Buse Sabiha Bozaslan was born in Istanbul in 1992 She graduated from Cumhuriyet University, the Department of Molecular Biology and Genetics in 2013 She has been a master student at Forensic Sciences Institute, Cerrahpaşa Medical Faculty since 2013. She won best scientific paper award in National Water and Health Congress, Antalya, 2015.

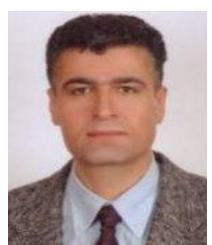

Huseyin Cakan is an associate professor in basic medical sciences, the Department of Institute of Forensic Sciences in Istanbul University. He took his $\mathrm{PhD}$ degree from Institute of Forensic Sciences in 2005. His research interest includes microbiology, forensic microbiology and water toxicology.

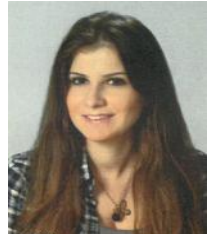

Perihan Seda Ates was born in Istanbul, in 1992. She graduated from Istanbul University, the Department of Molecular Biology and Genetics in 2013. She has been a master student at Forensic Sciences Institute, Cerrahpasa Medical Faculty since 2013. She won the best scientific paper award in National Water and Health Congress in Antalya, 2015.

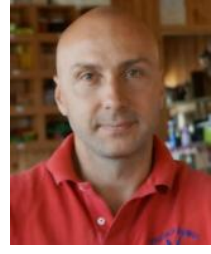

A. Ata Alturfan was born in 1971 in Istanbul, Turkey. $\mathrm{He}$ is an associate professor in the Institute of Forensic Sciences, in Istanbul University. He took his phD degree in biochemistry in 2007 from Marmara University. His research area includes water toxicity and microorganisms in wastewater. He has an international chapter and a national chapter related with water biochemistry and vitamins.

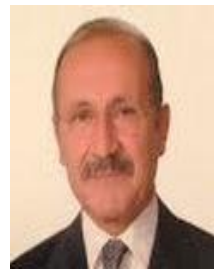

Salih Cengiz is a professor in basic forensic sciences, the Department of Institute of Forensic Sciences in Istanbul University. His research interest includes toxicity of metals, advanced analytical and toxicological methods, electronmicroscopy, auditing of toxicology and narcotic laboratories and reports, auditing of environmental-industrial toxicology and instrumental laboratories and auditing QC/QA systems of forensic laboratories. 